\title{
A Case of Bilateral Macular Holes Showing Onset and Spontaneous Closure over Very Short Intervals
}

\author{
Wataru Matsumiya Shigeru Honda Hisanori Imai \\ Sentaro Kusuhara Yasutomo Tsukahara Akira Negi \\ Department of Surgery, Division of Ophthalmology, Kobe University Graduate \\ School of Medicine, Kobe, Japan
}

\section{Key Words}

Bilateral macular holes · Early onset - Spontaneous closure · Vitreofoveal separation

\begin{abstract}
Purpose: Idiopathic macular holes (MHs) may occur bilaterally, and the spontaneous closure of MHs was documented previously. The median interval between the onset of $\mathrm{MHs}$ in each eye was reported to be 17.5 months.

Method: We report a case of bilateral MHs which occurred and resolved spontaneously over a very short interval.

Results: A 48-year-old woman with no history of ocular disease complained of a central scotoma and metamorphopsia in the left eye. Stage $1 \mathrm{~A} \mathrm{MH}$ was diagnosed in the left eye on the initial visit, which resolved spontaneously with vitreofoveal separation after 1 month. After an additional month, she complained of a similar visual disturbance in the right eye. Stage 1B MH was found in the right eye, which showed spontaneous closure after 1 month in the same manner as the left eye.

Conclusion: We present a unique case of bilateral MHs which occurred and resolved spontaneously within a very short time period. Careful observation of the non-involved eye is needed to address the risk of early onset bilateral MHs.
\end{abstract}

\section{Introduction}

Idiopathic macular hole $(\mathrm{MH})$ is a representative macular disease which causes metamorphopsia and central vision loss in the elderly, although its pathogenesis has not been sufficiently clarified. The clinical appearance and classification of MHs have been described by Gass and colleagues [1]. Stage $1 \mathrm{MH}$ usually shows metamorphopsia and/or mild visual disturbances. The spontaneous resolution of stage $1 \mathrm{MH}$, however, is often seen with vitreofoveal separation due to aging. The rate of spontaneous closure was 
reported as approximately $50 \%$ for stage $1 \mathrm{MH}$ [1]. Other previous studies reported the incidence of bilateral MHs as $10-20 \%$, including all stages in longitudinal observations [2, 3]. Lewis et al. [2] reported that the median interval between the onset of MHs in each eye was 17.5 months.

Here, we present a unique case of bilateral MHs which occurred and resolved spontaneously over a very short time interval. We observed a correlation between vitreofoveal separation and the spontaneous closure of the MHs using spectral domain optical coherent tomography (SD-OCT) (Cirrus HD-OCT; Carl Zeiss Meditec Inc., Germany).

\section{Case Report}

A 48-year-old woman, who had no history of ocular disease or trauma, complained of a central scotoma and metamorphopsia in the left eye. On the initial visit, her best-corrected visual acuity (BCVA) was 1.0 (decimal fraction) in each eye. The refraction was -5.0 diopters in each eye, and the axial length was $25.09 \mathrm{~mm}$ in the right eye and $25.10 \mathrm{~mm}$ in the left eye. Funduscopic examination showed a small MH in the left eye, and no particular findings in the right eye. OCT showed a stage 1A $\mathrm{MH}$ with vitreofoveal traction in the left eye (fig. 1a) and a perifoveal posterior vitreous detachment (PPVD) in the right eye (fig. 2a). She was kept under observation only, without any therapeutic intervention, because of her good visual acuity. One month later, the BCVA in her left eye was reduced to 0.9 . However, OCT showed a resolution of vitreofoveal traction and a spontaneous closure of the $\mathrm{MH}$ with slight residual subfoveal detachment (fig. 1b). The closure of the $\mathrm{MH}$ was almost complete after an additional month (fig. 1c).

Two months after the initial visit, she complained of a central scotoma and metamorphopsia in the right eye similar to what she had experienced in the left eye. At this time, her BCVA was 1.0 in the right eye. Funduscopic examination showed a small MH that was further confirmed by OCT, revealing a stage $1 \mathrm{~B}$ MH with vitreofoveal traction in the right eye (fig. $2 \mathrm{~b}$ ). She was kept under observation, again without any treatment, because visual acuity was again good. Two weeks later, her BCVA in the right eye was 0.8 , and OCT showed a spontaneous closure of the MH with vitreofoveal separation (fig. 2c). Eventually, her BCVA improved to 1.0 in both eyes 2 months after the original onset of the $\mathrm{MH}$.

\section{Discussion}

Gass [1] systematized the staging of MHs based on their clinical features, deducing that vitreofoveal traction accompanied by posterior vitreous detachment plays an important role in the formation of $\mathrm{MH}$. However, the detailed and structural relationship between posterior vitreous hyaloids and the retinal layers was unclear until Haouchine et al. [4] reported the first OCT-documented data showing detailed anatomic differences between stage $1 \mathrm{~A}$ and stage $1 \mathrm{~B}$ MHs. They proposed that a foveal pseudocyst in the inner retinal layer occurring due to a partial PPVD was the first step in full thickness $\mathrm{MH}$ formation. In addition, Michalewska et al. [5] hypothesized that the adherence of a posterior vitreous hyaloid to the retina transmits a traction force along the vitreous directly to the photoreceptor layer. Furthermore, Lipham et al. [6] suggested that the mechanism of $\mathrm{MH}$ formation may involve degenerative factors other than the tractional forces. However, the present case showed spontaneous closures of the MHs promptly after the resolution of the vitreofoveal tractions in both eyes, which suggests that the adhesion of a posterior vitreous hyaloid to the macula is an important factor in $\mathrm{MH}$ formation. Accordingly, the PPVD shown in figure $2 \mathrm{a}$ of the present case might be a premonitory phenomenon of MHs as reported by Chan et al. [7]. Moreover, SD-OCT revealed more detailed retinal 
structural changes during $\mathrm{MH}$ formation, such as a cone-shaped structure under the roof shown in figure $2 b$ in the present case, which contains the outer retina $[8,9]$.

It was interesting that the present case showed bilateral MHs within 2 months, which was much shorter than the median interval previously reported [2]. In addition, the MHs resolved spontaneously with similar vitreofoveal separations in both eyes. Since the refractions and axial lengths were very similar in both eyes in the present case, the aging changes at the vitreoretinal interface might occur symmetrically in both eyes. Spash et al. [10] also suggested that MH eyes had shorter axial lengths, and therefore the lower volume of the vitreous cavity might be a risk factor for developing incomplete and abnormal vitreous detachment. In our case, the axial lengths were about $25 \mathrm{~mm}$ in both eyes, and therefore a larger volume of the vitreous cavity might facilitate vitreofoveal separations.

To our knowledge, this is the first report describing a case of bilateral MHs that showed a very short time interval between the onset in both eyes, followed by prompt spontaneous closures along similar lines. Careful observation of the non-involved eye is needed to address the risk of early onset bilateral MHs. 


\begin{tabular}{c|l|l|l}
$\begin{array}{c}\text { Case Reports in } \\
\text { Ophthalmology }\end{array}$ & $\begin{array}{l}\text { Case Rep Ophthalmol 2010;1:47-52 } \\
\text { DOl: 10.1159/000320586 }\end{array}$ & $\begin{array}{l}\text { Published online: } \\
\text { September 13, 2010 }\end{array}$ & $\begin{array}{l}\text { O 2010 S. Karger AG, Basel } \\
\text { ISSN 1663-2699 } \\
\text { www.karger.com/cop }\end{array}$ \\
\hline
\end{tabular}
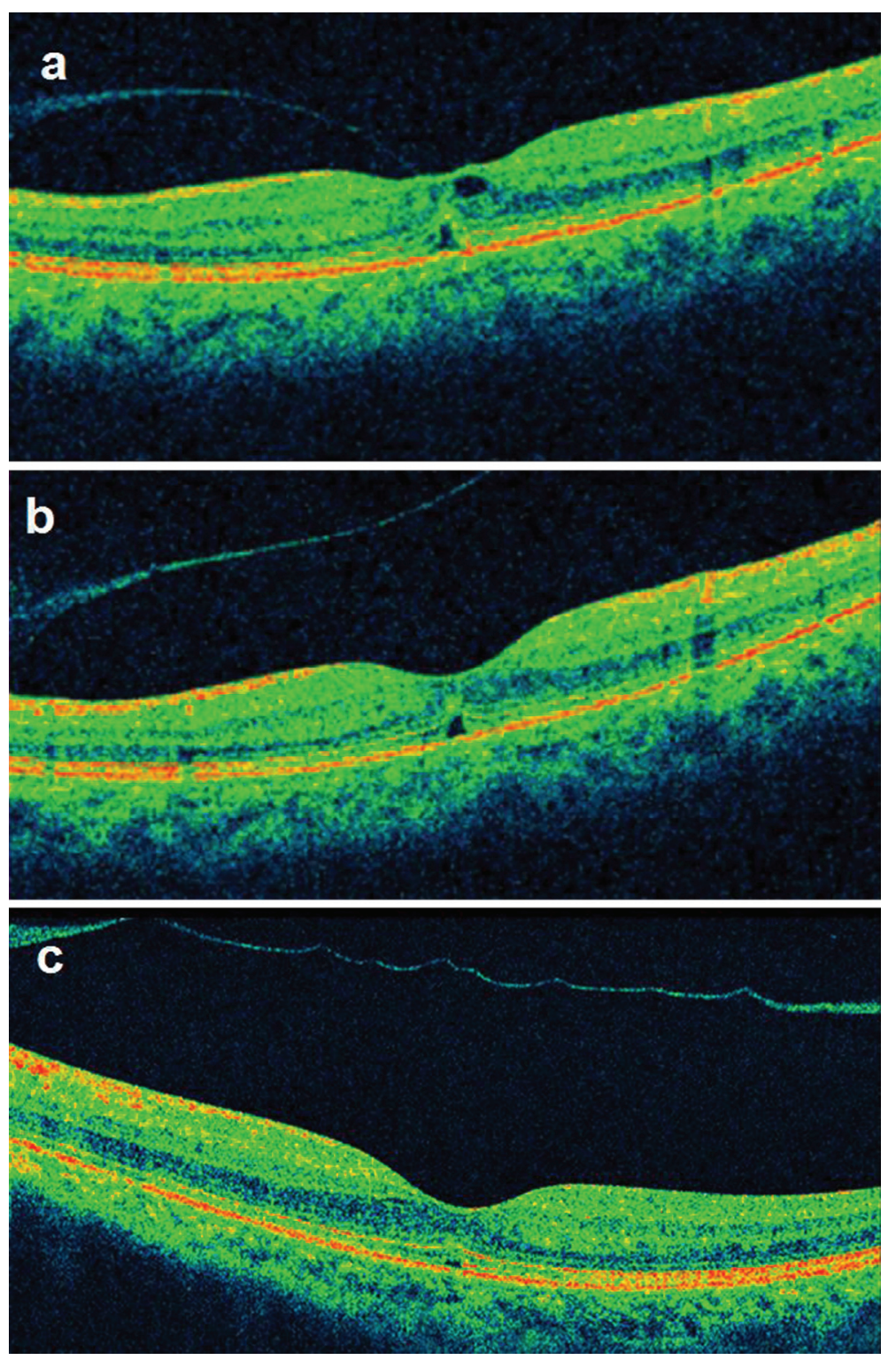

Fig. 1. SD-OCT images of the left eye. a A typical stage $1 \mathrm{~A} \mathrm{MH}$ was present on the initial visit. Intraretinal splits and a small triangularly-shaped foveal detachment were observed, with a PPVD. b One month later, the MH spontaneously resolved with vitreofoveal separation, but a slight subfoveal detachment was residual. c One additional month later, no photoreceptor defects were visible, and the subfoveal detachment was not detectable. 


\begin{tabular}{l|l|l|l} 
Case Reports in & $\begin{array}{l}\text { Case Rep Ophthalmol 2010;1:47-52 } \\
\text { DOI: 10.1159/000320586 }\end{array}$ & $\begin{array}{l}\text { Published online: } \\
\text { September 13, 2010 }\end{array}$ & $\begin{array}{l}\odot \text { 2010 S. Karger AG, Basel } \\
\text { ISN 1663-2699 } \\
\text { www.karger.com/cop }\end{array}$ \\
\hline
\end{tabular}
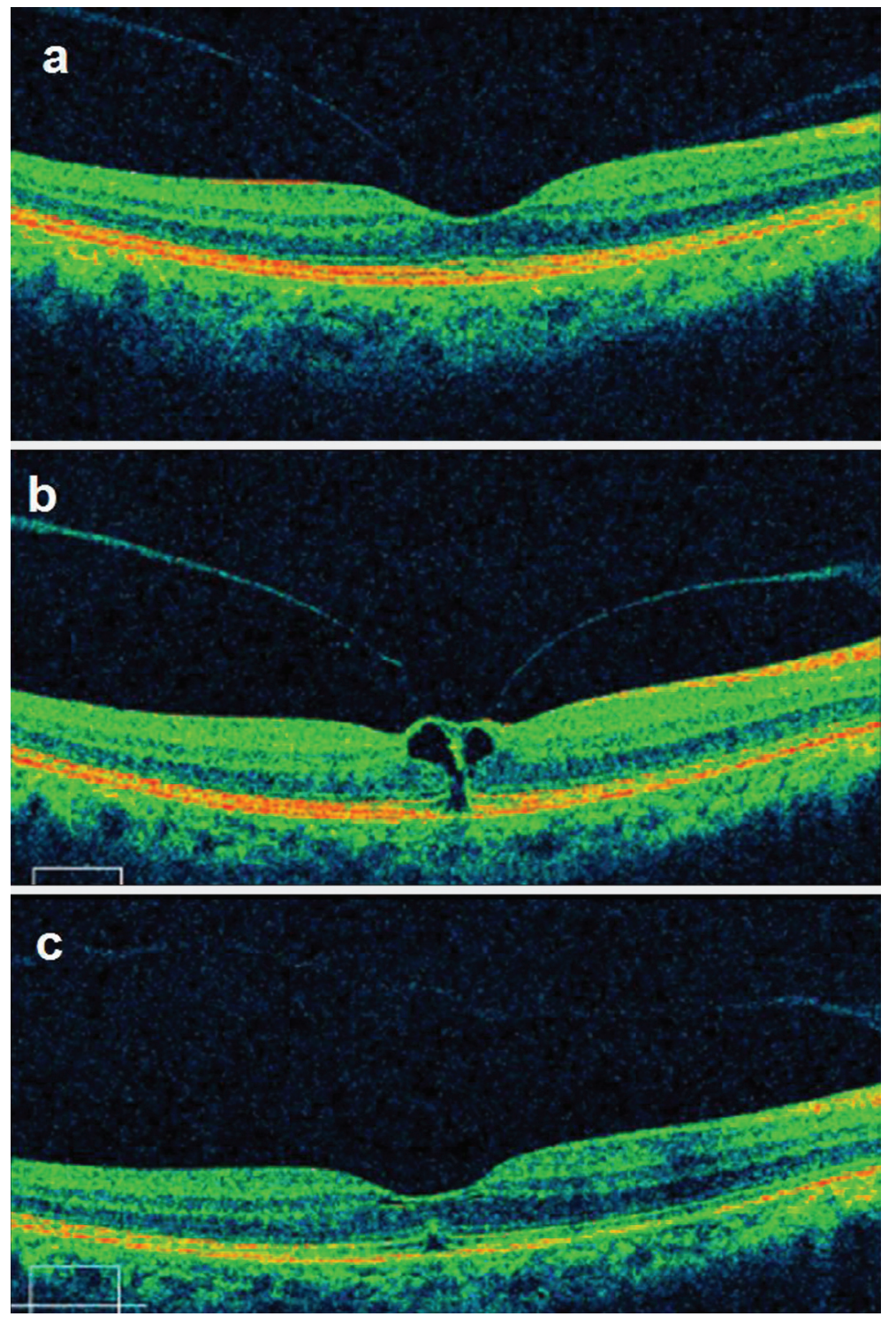

Fig. 2. SD-OCT images of the right eye. a PPVD was present, but no disarray was found in the fovea on the initial visit. b A typical stage 1B MH with PPVD was present at 2 months after the initial visit. A foveal pseudocyst and a disruption of the outer retinal layer with an inner roof were observed. A coneshaped structure under the roof was also seen. c One additional month later, the MH resolved spontaneously with vitreofoveal separation, but a gap in the outer retina and slight splits in the inner retina were present at the fovea.

\section{References}

1 Gass JDM: Idiopathic senile macular hole: its early stages and pathogenesis. Arch Ophthalmol 1988;106:629639.

2 Lewis ML, Cohen SM, Smiddy WE, Gass JD: Bilaterality of idiopathic macular holes. Graefes Arch Clin Exp Ophthalmol 1996;234:241-245.

3 McCannel CA, Ensminger JL, Diehl NN, Hodge DN: Population-based incidence of macular holes: Ophthalmology 2009;116:1366-1369. 
4 Haouchine B, Massin P, Gaudric A: Foveal pseudocyst as the first step in macular hole formation: a prospective study by optical coherence tomography. Ophthalmology 2001;108:15-22.

5 Michalewska Z, Michalewski J, Sikorski BL, Kałuzny JJ, Wojtkowski M, Adelman RA, Nawrocki J: A study of macular hole formation by serial spectral optical coherence tomography. Clin Experiment Ophthalmol 2009;37:373-383.

6 Lipham WJ, Smiddy WE: Idiopathic macular hole following vitrectomy: implications for pathogenesis. Ophthalmic Surg Lasers 1997;28:633-639.

7 Chan A, Duker JS, Schuman JS, Fujimoto JG: Stage 0 macular holes: observations by optical coherence tomography. Ophthalmology 2004;111:2027-2032.

8 Hangai M, Ojima Y, Gotoh N, et al: Three-dimensional imaging of macular holes with high-speed optical coherence tomography. Ophthalmology 2007;114:763-773.

-9 Takahashi A, Nagaoka T, Ishiko S, Kameyama D, Yoshida A: Foveal anatomic changes in a progressing stage1 macular hole documented by spectral-domain Optical Coherence Tomography. Ophthalmology 2010;117:806810 .

10 Shah SP, Bunce C, Johnston RL, Laidlaw DA: Are biometric parameters a risk factor for idiopathic macular hole formation? Results of a matched case-control series. Br J Ophthalmol 2006;90:117-118. 